FERNANDES, AM; SORATTO, RP; EVANGELISTA, RM; JOB, ALG. 2016. Influência do fósforo na qualidade e produtividade de tubérculos de cultivares de batata de duplo propósito. Horticultura Brasileira 34: 346-355. DOI - http://dx.doi.org/10.1590/S0102-05362016003007

\title{
Influência do fósforo na qualidade e produtividade de tubérculos de cultivares de batata de duplo propósito
}

\author{
Adalton M Fernandes ${ }^{1}$; Rogério P Soratto²; Regina M Evangelista ${ }^{2}$; André LG Job ${ }^{2}$ \\ ${ }^{1}$ Universidade Estadual Paulista (UNESP-CERAT), Botucatu-SP, Brasil; adalton@cerat.unesp.br; ${ }^{2}$ Universidade Estadual Paulista \\ (UNESP-FCA), Botucatu-SP, Brasil; soratto@fca.unesp.br; evangelista@fca.unesp.br; andreljob@hotmail.com
}

\section{RESUMO}

Mesmo em áreas com teores mais elevados de fósforo $(\mathrm{P})$ disponível no solo é comum observar a aplicação de doses deste nutriente, com o objetivo de aumentar a produtividade e o tamanho dos tubérculos de batata. Contudo, nesses casos não se sabe até que ponto o uso de elevadas doses de $\mathrm{P}$ pode afetar a produtividade e as características de qualidade dos tubérculos. Objetivou-se com este trabalho avaliar a influência da adubação fosfatada sobre a produtividade e as características de qualidade dos tubérculos de cultivares de batata de duplo propósito, cultivadas em solos com baixo (14 mg/ $\left.\mathrm{dm}^{3}\right)$, médio $\left(36 \mathrm{mg} / \mathrm{dm}^{3}\right)$ e alto $\left(70 \mathrm{mg} / \mathrm{dm}^{3}\right)$ teores de $\mathrm{P}$ disponível. Nos três solos, utilizou-se o delineamento de blocos ao acaso, no esquema fatorial $2 \times 5$, com quatro repetições. Os tratamentos foram constituídos por duas cultivares de batata (Asterix e Markies) e cinco doses de $\mathrm{P}_{2} \mathrm{O}_{5}(0,125,250,500$ e $1.000 \mathrm{~kg} / \mathrm{ha})$. A cultivar Markies foi menos produtiva que a Asterix, mas com tubérculos de qualidade superior nas características firmeza, sólidos solúveis, acidez titulável, $\mathrm{pH}$ da polpa e teor de proteína. Em solo com baixa, média e alta disponibilidade de $\mathrm{P}$, as produtividades de tubérculos comercializáveis, de ambas cultivares, foram incrementadas em $376 \%, 41 \%$ e $26 \%$, respectivamente, até doses de máxima eficiência agronômica de 500, 255 e $239 \mathrm{~kg} /$ ha de $\mathrm{P}_{2} \mathrm{O}_{5}$. Sob baixa disponibilidade de $\mathrm{P}$, a adubação fosfatada aumentou a massa média, a firmeza, o $\mathrm{pH}$ da polpa e o teor de amido, e diminuiu o teor de açúcares redutores dos tubérculos. Nos solos com maiores teores de $\mathrm{P}$ disponível, além de ter exercido menor influência sobre a produtividade e qualidade dos tubérculos, a adubação fosfatada aumentou os teores de açúcares redutores dos tubérculos até a dose de $453 \mathrm{~kg} /$ ha de $\mathrm{P}_{2} \mathrm{O}_{5}$, o que não é interessante para o processamento industrial da batata.

Palavras-chave: Solanum tuberosum, produtividade comercial, açúcares redutores, amido, disponibilidade de nutriente.

\section{ABSTRACT}

Phosphorus influence on quality and yield of tubers of dual purpose potato cultivars

Even in areas with high levels of phosphorus (P) available in the soil, application of this nutrient is common, aiming to increase potato tuber yield and size. However, the effect of high $\mathrm{P}$ rates on tuber yield and quality is not known in these cases. The objective of this study was to evaluate the influence of $\mathrm{P}$ fertilization on yield and characteristics of tuber quality of dual purpose potato cultivars, grown in soils with low $\left(14 \mathrm{mg} / \mathrm{dm}^{3}\right)$, medium $\left(36 \mathrm{mg} / \mathrm{dm}^{3}\right)$ and high $\left(70 \mathrm{mg} / \mathrm{dm}^{3}\right) \mathrm{P}$ availability. In the three soils, we used the randomized blocks design in a $2 \times 5$ factorial scheme, with four replications. The treatments consisted of two potato cultivars (Asterix and Markies) and five $\mathrm{P}_{2} \mathrm{O}_{5}$ rates $(0,125,250,500$, and $1,000 \mathrm{~kg} / \mathrm{ha})$. The cultivar Markies was less productive than Asterix but had tubers with higher quality characteristics, such as firmness, soluble solids, titratable acidity, pulp $\mathrm{pH}$ and protein concentration. In soils with low, medium and high $\mathrm{P}$ availability, the marketable tuber yield of both cultivars was increased by $376 \%, 41 \%$, and $26 \%$, respectively, up to maximum agronomic rates of 500, 255, and $239 \mathrm{~kg} / \mathrm{ha} \mathrm{P}_{2} \mathrm{O}_{5}$. Under low $\mathrm{P}$ availability, fertilization increased the average weight, firmness, pulp $\mathrm{pH}$ and starch concentration, and decreased the reducing sugar concentration in tubers. In soils with higher $\mathrm{P}$ availability, besides having exercised less influence on the yield and quality of tubers, the phosphate fertilizer increased levels of reducing sugars in tubers up to the rate of $453 \mathrm{~kg} / \mathrm{ha} \mathrm{P}_{2} \mathrm{O}_{5}$, which is not interesting for the industrial processing of potatoes.

Keywords: Solanum tuberosum, marketable yield, reducing sugars, starch, nutrient availability.

(Recebido para publicação em 14 de outubro de 2014; aceito em 7 de janeiro de 2016)

(Received on October 14, 2014; accepted on January 7, 2016)

\begin{abstract}
$\mathrm{A}$ batata (Solanum tuberosum) é um dos alimentos mais consumidos no mundo e um dos dez principais produtos agrícolas brasileiros. Essa cultura caracteriza-se por apresentar sistema radicular superficial, ciclo curto e elevada produtividade, fatores esses que fazem com que a batateira exija quantidades relativamente grandes de nutrientes (Fernandes et al., 2011a;
\end{abstract}

Soratto et al., 2011).

Assim, por ser um cultivo de custo elevado, muitos produtores não acatam as recomendações técnicas de adubação (Nava et al., 2007; Fernandes et al., 2011a) e utilizam altas doses de fertilizantes no momento do plantio na expectativa de garantirem elevadas produtividades (Quadros et al., 2009). Nesse cenário, o fósforo $(\mathrm{P})$ tem sido o nutriente aplicado em maiores quantidades, por causa da sua baixa disponibilidade e elevada fixação na maioria dos solos brasileiros (Fernandes \& Soratto, 2012). Porém, mesmo em áreas com teores mais elevados de $\mathrm{P}$ disponível é comum observar a aplicação de altas doses deste nutriente, com o objetivo de aumentar a produtividade e o tamanho dos tubérculos produzidos. 
Esse nutriente, além de interferir na síntese de amido (Houghland, 1960; Stark et al., 2003; Rosen et al., 2014), pode influenciar também várias características ligadas à qualidade dos tubérculos, como o tamanho e peso específico (Freeman et al., 1998; Rosen et al., 2014), a percentagem de matéria seca (MS) e os teores de amido (Rosen et al., 2014), ácido ascórbico e proteína (Klein et al., 1980) dos tubérculos, sendo dessa forma, um nutriente importante para melhorar o valor nutritivo dos tubérculos da batateira (Klein et al., 1980).

Tubérculos de boa qualidade são de fundamental importância para a indústria de processamento, pois aqueles com maiores percentuais de MS e amido favorecem o rendimento de fritura, proporcionando menor retenção de óleo, garantindo a crocância e a textura do produto final (Fernandes et al., 2010). Contudo, muitos dos efeitos positivos do $\mathrm{P}$ sobre a qualidade dos tubérculos não são observados quando a disponibilidade desse nutriente no solo é elevada (Hochmuth et al., 2002; Rosen \& Bierman, 2008). Dessa forma, é de fundamental importância conhecer melhor a influência que o $\mathrm{P}$ pode exercer sobre as características de qualidade dos tubérculos, tendo em vista que o consumo de batata industrializada no Brasil tem aumentado expressivamente nos últimos anos (Evangelista et al., 2011). Especialmente no seguimento de palitos pré-fritos congelados, as quantidades consumidas pela população brasileira quase dobraram de volume nos últimos seis anos (Ramos et al., 2013).

Nesse mercado de batata industrializada a cultivar Asterix tem se destacado, porque apresenta tubérculos com formato uniforme e alongado e com percentual elevado de MS. No entanto, a falta de matéria prima em quantidade e qualidade adequadas tem levado à busca por novas cultivares de batata, com alta qualidade para o processamento, adaptadas às condições brasileiras de cultivo (Müller et al., 2009), e que atendam às características desse mercado consumidor. Recentemente, a cultivar Markies, que apresenta tubérculos com características similares aos da cultivar Asterix (Fernandes et al., 2010; Evangelista et al., 2011), começou a ser cultivada no Brasil em extensões de áreas bastante significativas e passou a ser uma das cinco cultivares de batata mais plantadas no país (ABBA, 2010). Além disso, os tubérculos das cultivares Asterix e Markies também têm sido comercializados in natura, tendo boa aceitação em algumas regiões. Em casa de vegetação, Soratto et al. (2015) verificaram que a cultivar Asterix foi mais responsiva ao fornecimento de $\mathrm{P}$ que a Markies, pelo fato da disponibilidade de $\mathrm{P}$ no solo interferir de forma diferente na alocação de fotoassimilados para os tubérculos destas duas cultivares. No entanto, não se sabe como a adubação fosfatada pode interferir na qualidade dos tubérculos dessas cultivares, quando elas são cultivadas em solos com diferentes disponibilidades de $\mathrm{P}$.

Dessa forma, objetivou-se com este trabalho, avaliar a influência da adubação fosfatada sobre a produtividade e as características de qualidade dos tubérculos comercializáveis das cultivares Asterix e Markies, cultivadas em solos com diferentes teores de $\mathrm{P}$ disponível.

\section{MATERIAL E MÉTODOS}

Foram conduzidos três experimentos no ano de 2011, em áreas de produção de batata, dos municípios de Avaré-SP, Itaí-SP e Cerqueira César-SP, em Latossolos Vermelhos distróficos, respectivamente, com baixo (14 mg/ $\mathrm{dm}^{3}$ ), médio $\left(36 \mathrm{mg} / \mathrm{dm}^{3}\right)$ e alto $(70$ $\mathrm{mg} / \mathrm{dm}^{3}$ ) teores de $\mathrm{P}$ (resina) (Raij et al., 1997). Em todos os experimentos o preparo do solo foi realizado de forma convencional, com aração e gradagens. Apenas na área com baixo teor de $\mathrm{P}$, realizou-se calagem aplicando-se 2,5 t/ha de calcário dolomítico. Antes da instalação dos experimentos, coletaram-se amostras de solo na camada de 0-20 cm para determinação das características químicas das áreas experimentais (Raij et al., 2001). O solo com baixa disponibilidade de $\mathrm{P}$ apresentou: matéria orgânica, 47,6 g/dm 3 ; $\mathrm{pH}\left(\mathrm{CaCl}_{2}\right), 5,7$; $\mathrm{K}, \mathrm{Ca}, \mathrm{Mg}$ e $\mathrm{H}+\mathrm{Al}, 2,3,59,7,19,3$ e $26,9 \mathrm{mmol} / \mathrm{dm}^{3}$, respectivamente; $\mathrm{V}=$ $75 \%$ e teores de argila, silte e areia de 400,289 e $311 \mathrm{~g} / \mathrm{kg}$, respectivamente. No solo com média disponibilidade de
P a composição era: matéria orgânica, $26,7 \mathrm{~g} / \mathrm{m}^{3} ; \mathrm{pH}\left(\mathrm{CaCl}_{2}\right), 4,8 ; \mathrm{K}, \mathrm{Ca}, \mathrm{Mg}$ e $\mathrm{H}+\mathrm{Al}, 2,3,31,5,10,7$ e 45,7 $\mathrm{mmol}_{\mathrm{c}}$ / $\mathrm{dm}^{3}$, respectivamente; $\mathrm{V}=49 \%$ e teores de argila, silte e areia de 524, 184 e 292 $\mathrm{g} / \mathrm{kg}$, respectivamente. $\mathrm{O}$ solo com alta disponibilidade de $\mathrm{P}$ apresentava: matéria orgânica, $27,8 \mathrm{~g} / \mathrm{dm}^{3} ; \mathrm{pH}\left(\mathrm{CaCl}_{2}\right)$, 4,8; K, Ca, Mg e H+Al, 3,3, 30,9, 9,0 e $50,8 \mathrm{mmol} / \mathrm{dm}^{3}$, respectivamente; $\mathrm{V}=$ $46 \%$ e teores de argila, silte e areia de 602,245 e $153 \mathrm{~g} / \mathrm{kg}$, respectivamente.

Os experimentos foram conduzidos no delineamento experimental de blocos ao acaso, no esquema fatorial $2 \times 5$, com quatro repetições. Os tratamentos foram constituídos por duas cultivares de batata (Asterix e Markies) e cinco doses de $\mathrm{P}_{2} \mathrm{O}_{5}(0,125,250,500$ e $1.000 \mathrm{~kg} / \mathrm{ha})$. Cada parcela experimental foi constituída por cinco fileiras de plantas de $5 \mathrm{~m}$ de comprimento. A área útil foi constituída pelas três fileiras centrais, desprezando-se 0,50 $\mathrm{m}$ em ambas as extremidades de cada fileira. No sulco de plantio, além das doses de $\mathrm{P}_{2} \mathrm{O}_{5}$, foram aplicados 62 $\mathrm{kg} /$ ha de $\mathrm{N}$ (sulfato de amônio) e 124 $\mathrm{kg} /$ ha de $\mathrm{K}_{2} \mathrm{O}$ (cloreto de potássio) em todos os experimentos. Como fonte de $\mathrm{P}$ foi utilizado o superfosfato triplo.

O plantio dos tubérculos-semente tipo III (massa média de $35 \mathrm{~g}$ ) foi efetuado no espaçamento de $0,80 \mathrm{~m}$ entre fileiras e $0,30 \mathrm{~m}$ entre tubérculos-semente. A adubação nitrogenada de cobertura foi realizada aos 22, 24 e 28 dias após o plantio (DAP) e utilizando 43, 64 e $41 \mathrm{~kg} / \mathrm{ha}$ de $\mathrm{N}$ nas áreas com baixa, média e alta disponibilidade de $\mathrm{P}$, respectivamente. A fonte de $\mathrm{N}$ usada na adubação de cobertura foi a ureia ( $45 \%$ de N) nas áreas com baixa e média disponibilidade de $\mathrm{P}$ e o nitromag (27\% de $\mathrm{N}, 4 \%$ de $\mathrm{Ca}$ e $2 \%$ de $\mathrm{Mg}$ ) na área com alta disponibilidade de P. Após a adubação nitrogenada de cobertura foi efetuada a amontoa.

Nas áreas com baixo, médio e alto teor de $\mathrm{P}$ disponível, a dessecação da parte aérea da cultura foi realizada aos 112, 94 e 97 DAP, respectivamente. A colheita dos tubérculos foi realizada, em média, aos 21 dias após a dessecação das plantas. Os tubérculos colhidos foram lavados, classificados pelo diâmetro transversal e considerados comercializáveis aqueles com diâmetro acima de 
$23 \mathrm{~mm}$. Em seguida, os tubérculos foram contados e pesados para a determinação da produtividade e da massa média de tubérculos comercializáveis. A firmeza foi determinada em três tubérculos (com casca) de cada parcela, utilizando-se texturômetro, com profundidade de penetração de $20 \mathrm{~mm}$ e velocidade de 2,0 $\mathrm{mm} / \mathrm{s}$ e ponteira TA $9 / 1000$. Na quantificação dos sólidos solúveis (SS) algumas fatias da polpa foram maceradas e duas gotas do suco foram colocadas no prisma do refratômetro eletrônico e após um minuto fez-se a leitura direta dos mesmos sendo expressos em ${ }^{\circ}$ Brix.

Para a determinação da acidez titulável $10 \mathrm{~g}$ de polpa triturada foram diluídas em $100 \mathrm{~mL}$ de água destilada e a mistura foi filtrada e titulada com solução hidróxido de sódio a $0,1 \mathrm{~N}$, tendo como indicador fenolftaleína (Zenebom \& Pascuet, 2005). A determinação do $\mathrm{pH}$ foi realizada diretamente na polpa triturada utilizando $\mathrm{pHmetro}$ digital (Zenebom \& Pascuet, 2005). O percentual de MS foi determinado por meio da secagem da polpa dos tubérculos em estufa a $105^{\circ} \mathrm{C}$ com circulação de ar até peso constante (Zenebom \& Pascuet, 2005). Os teores de açúcares redutores e amido foram determinados na MS, segundo metodologia descrita por Somogyi, adaptada por Nelson (1944) e as leituras realizadas em espectrofotômetro a 535 $\mathrm{nm}$. Em seguida, os dados de açúcares e de amido foram convertidos para teores na matéria fresca. $\mathrm{O}$ teor de proteína nos tubérculos foi determinado na matéria seca, com o método de Kjeldahl (Horwitz \& Latimer Junior, 2005) e com o fator de 6,25 para conversão em proteína bruta. Em seguida, os dados foram convertidos para teores de proteína na matéria fresca.

Os resultados de cada experimento foram submetidos à análise de variância separadamente. Para o efeito isolado do fator cultivar foi utilizado apenas o teste $F(p<0,05)$, enquanto os efeitos das doses de $\mathrm{P}$ foram avaliados por análise de regressão. No desdobramento das interações significativas as médias das cultivares foram comparadas pelo teste $t$ (DMS) $(p<0,05)$. As regressões foram determinadas usando o SAS PROC NLIN, determinando melhor ajuste para cada conjunto de dados. A dose de máxima eficiência agronômica (DMEA) foi obtida por meio da estimativa da dose de $\mathrm{P}_{2} \mathrm{O}_{5}$ que alcançou o ponto de inflexão e/ou estabilização da produtividade comercial. A partir da equação ajustada para a produtividade comercial, em cada condição de disponibilidade de $\mathrm{P}$ no solo, foi calculada a dose de máxima eficiência econômica (DMEE), ou seja, a dose de $\mathrm{P}_{2} \mathrm{O}_{5}(\mathrm{~kg} / \mathrm{ha})$ em que $\mathrm{R} \$ 1,00$ de $\mathrm{P}_{2} \mathrm{O}_{5}$ adicional retornaria $\mathrm{R} \$ 1,00$ de batata produzida. A DMEE foi calculada igualando-se a derivada primeira de cada equação com a relação de preços do fertilizante fosfatado e da batata (Fontes et al., 1997; Bélanger et al., 2000). A relação de preços foi calculada considerando o preço médio ( $\mathrm{R} \$ 0,94 /$ $\mathrm{kg}$ ) da batata comercializada em São Paulo durante o ano de 2011 (CEPEA/ ESALQ/USP, 2012) e o preço do $\mathrm{P}_{2} \mathrm{O}_{5}$ do superfosfato triplo ( $\mathrm{R} \$ 4,46 / \mathrm{kg}$ ).

\section{RESULTADOS E DISCUSSÃO}

Nos três experimentos, a produtividade de tubérculos comercializáveis foi influenciada apenas pelos fatores isolados (Tabela 1). As produtividades mais elevadas foram obtidas com a cultivar Asterix. Fernandes et al. (2011b) também observaram produtividades mais elevadas da cultivar Asterix em relação a cultivar Markies em experimento conduzido em solo com elevado teor de $\mathrm{P}$ disponível $\left(\mathrm{P}_{\text {resina }}=70 \mathrm{mg} / \mathrm{dm}^{3}\right)$. A adubação fosfatada aumentou a produtividade de tubérculos comercializáveis nos três experimentos, porém, com respostas diferentes (Figuras 1a, 2a e 3a). No solo com baixa disponibilidade de $\mathrm{P}$, houve incremento de $376 \%$ e até DMEA de $500 \mathrm{~kg} / \mathrm{ha}$ de $\mathrm{P}_{2} \mathrm{O}_{5}$ (Figura 1a e Tabela 2). Neste solo o teor de matéria orgânica era maior. No solo, a matéria orgânica pode tanto adsorver o $\mathrm{P}$ como também bloquear os sítios de adsorção que ocorrem nas superfícies das argilas e dos óxidos de ferro e alumínio (Sanyal \& De Datta, 1991). A DMEE no solo com baixa disponibilidade de $\mathrm{P}$ foi de $358 \mathrm{~kg} /$ ha de $\mathrm{P}_{2} \mathrm{O}_{5}$ (Tabela 2 e Figura 1a). Isso demonstra que a DMEE no solo com baixa disponibilidade de $\mathrm{P}$ foi $28 \%$ menor que a DMEA (500 kg/ha de $\mathrm{P}_{2} \mathrm{O}_{5}$ ). Fontes et al. (1997) também verificaram, em solo com baixa disponibilidade de $\mathrm{P}$,
DMEE 39\% inferior à DMEA, porém, os autores observaram DMEA $(867 \mathrm{~kg}$ / ha de $\left.\mathrm{P}_{2} \mathrm{O}_{5}\right)$ e DMEE $\left(530 \mathrm{~kg} /\right.$ ha de $\left.\mathrm{P}_{2} \mathrm{O}_{5}\right)$ maiores que as observadas no presente trabalho. Nos solos com média e alta disponibilidades de $\mathrm{P}$ os aumentos na produtividade comercial foram de $41 \%$ e $26 \%$, respectivamente, e ocorreram somente até as DMEA de 255 e $239 \mathrm{~kg} / \mathrm{ha}$ de $\mathrm{P}_{2} \mathrm{O}_{5}$, respectivamente (Figuras $2 \mathrm{a} e$ $3 a)$. No solo com média disponibilidade de $\mathrm{P}$, devido ao fato dos dados terem se ajustado a uma equação linear-platô, a DMEE foi a mesma considerada DMEA $(255 \mathrm{~kg} / \mathrm{ha})$. Já no solo com alta disponibilidade de $\mathrm{P}$ a DMEE foi de $220 \mathrm{~kg} /$ ha de $\mathrm{P}_{2} \mathrm{O}_{5}$, ou seja, um pouco inferior à DMEA. Verifica-se que nos solos com maior disponibilidade de $\mathrm{P}$ a resposta da cultura ao $\mathrm{P}$ foi menor (Figuras 1a, 2a e 3a), apesar dos maiores teores de argila desses solos poderem também ter aumentado a adsorção dos íons fosfato no solo (Novais \& Smyth, 1999). Outros autores também verificaram que as maiores respostas da batateira ao $\mathrm{P}$ ocorrem em solos com baixos teores de $\mathrm{P}$ disponível (Fernandes \& Soratto, 2012), e que a aplicação de elevadas doses de $\mathrm{P}$ em solos com média e alta disponibilidade desse nutriente não aumenta a produtividade de tubérculos (Rosen \& Bierman, 2008).

Vale destacar que a resposta econômica da cultura ao $\mathrm{P}$ (DMEE) pode ser alterada de acordo com a variação na relação entre os preços do fertilizante fosfatado e da batata, em função da sazonalidade de preços, sendo que menores valores desta relação proporcionaria DMEE mais próxima da DMEA, o que também foi relatado em estudo avaliando a resposta da batateira à adubação com o fertilizante NPK 4-14-8 (Queiroz et al., 2013).

Neste estudo, as cultivares estudadas responderam a doses de fertilizante fosfatado superiores àquelas recomendadas para a cultura da batata no estado de São Paulo (Figuras 1a, 2a e 3a e Tabela 2), as quais são de 300,200 e $100 \mathrm{~kg} / \mathrm{ha}$ de $\mathrm{P}_{2} \mathrm{O}_{5}$, para solos com baixa, média e alta disponibilidade de $\mathrm{P}$, respectivamente (Miranda Filho, 1997). Estes resultados sugerem que as cultivares Asterix e Markies podem responder economicamente a doses de $\mathrm{P}_{2} \mathrm{O}_{5}$ no sulco de 
Tabela 1. Produtividade e características de qualidade em tubérculos comercializáveis de cultivares de batata em resposta à adubação fosfatada em solos com baixa, média e alta disponibilidade de $\mathrm{P}$, e análise de variância (yield and quality characteristics of marketable tubers of potato cultivars in response to P fertilization in soils with low, medium, and high P availability, and analyses of variance). Botucatu, UNESP, 2011.

\begin{tabular}{|c|c|c|c|c|c|}
\hline \multirow{2}{*}{ Variáveis } & \multicolumn{2}{|c|}{ Cultivares } & \multicolumn{3}{|c|}{ ANOVA $(\mathrm{P}>\mathrm{F})$} \\
\hline & Asterix & Markies & Cultivar (C) & Dose (D) & CXD \\
\hline & \multicolumn{5}{|c|}{ Baixa disponibilidade de $\mathrm{P}\left(14 \mathrm{mg} / \mathrm{dm}^{3}\right)^{5}$} \\
\hline $\mathrm{PC}(\mathrm{t} / \mathrm{ha})^{1}$ & $16,71 \mathrm{a}$ & $14,53 b$ & 0,004 & $<0,001$ & 0,651 \\
\hline $\operatorname{MMTC}(g)^{2}$ & $63,80 \mathrm{a}$ & $61,40 \mathrm{a}$ & 0,297 & $<0,001$ & 0,174 \\
\hline Firmeza $(\mathrm{N})$ & $8,10 \mathrm{~b}$ & $9,50 \mathrm{a}$ & $<0,001$ & 0,021 & 0,888 \\
\hline Sólidos solúveis ( $\left.{ }^{\circ} \mathrm{Brix}\right)$ & $4,50 \mathrm{~b}$ & $5,30 \mathrm{a}$ & $<0,001$ & 0,118 & 0,719 \\
\hline Acidez titulável $^{3}$ & $0,14 \mathrm{~b}$ & $0,16 \mathrm{a}$ & $<0,001$ & 0,574 & 0,769 \\
\hline pH da polpa & $6,00 \mathrm{~b}$ & $6,20 \mathrm{a}$ & $<0,001$ & 0,043 & 0,808 \\
\hline Matéria seca (\%) & $17,20 \mathrm{a}$ & $17,50 \mathrm{a}$ & 0,412 & 0,068 & 0,081 \\
\hline Amido $(\%)^{4}$ & $10,50 \mathrm{a}$ & $10,20 \mathrm{a}$ & 0,400 & $<0,001$ & 0,620 \\
\hline Açúcares redutores $(\%)^{4}$ & $0,08 \mathrm{a}$ & $0,07 \mathrm{a}$ & 0,053 & $<0,001$ & 0,300 \\
\hline \multirow[t]{2}{*}{ Teor de proteína $(\%)^{4}$} & $1,90 \mathrm{~b}$ & $2,50 \mathrm{a}$ & $<0,001$ & 0,054 & 0,240 \\
\hline & \multicolumn{5}{|c|}{ Média disponibilidade de $\mathrm{P}\left(36 \mathrm{mg} / \mathrm{m}^{3}\right)^{5}$} \\
\hline $\mathrm{PC}(\mathrm{t} / \mathrm{ha})^{1}$ & $35,48 \mathrm{a}$ & $28,73 b$ & $<0,001$ & $<0,001$ & 0,764 \\
\hline $\operatorname{MMTC}(g)^{2}$ & $110,70 \mathrm{a}$ & $118,60 \mathrm{a}$ & 0,078 & 0,018 & 0,505 \\
\hline Firmeza $(\mathrm{N})$ & $9,30 \mathrm{~b}$ & $9,50 \mathrm{a}$ & 0,020 & 0,026 & 0,122 \\
\hline Sólidos solúveis ( ${ }^{\circ}$ Brix) & $4,80 \mathrm{~b}$ & $5,70 \mathrm{a}$ & $<0,001$ & 0,200 & 0,490 \\
\hline Acidez titulável $^{3}$ & $0,15 b$ & $0,19 \mathrm{a}$ & $<0,001$ & 0,077 & 0,182 \\
\hline pH da polpa & $6,10 \mathrm{~b}$ & $6,30 \mathrm{a}$ & $<0,001$ & 0,053 & 0,014 \\
\hline Matéria seca (\%) & $18,60 \mathrm{~b}$ & $19,30 \mathrm{a}$ & 0,032 & 0,235 & 0,142 \\
\hline Amido $(\%)^{4}$ & $15,90 \mathrm{a}$ & $14,50 \mathrm{~b}$ & 0,001 & 0,056 & 0,998 \\
\hline Açúcares redutores $(\%)^{4}$ & $0,11 \mathrm{~b}$ & $0,13 a$ & $<0,001$ & 0,202 & 0,087 \\
\hline \multirow[t]{2}{*}{ Teor de proteína $(\%)^{4}$} & $1,90 \mathrm{~b}$ & $2,30 \mathrm{a}$ & $<0,001$ & 0,876 & 0,558 \\
\hline & \multicolumn{5}{|c|}{ Alta disponibilidade de $P\left(70 \mathrm{mg} / \mathrm{dm}^{3}\right)^{5}$} \\
\hline $\mathrm{PC}(\mathrm{t} / \mathrm{ha})^{1}$ & $35,83 a$ & $30,38 b$ & $<0,001$ & $<0,001$ & 0,902 \\
\hline $\operatorname{MMTC}(g)^{2}$ & $110,20 \mathrm{a}$ & $114,40 \mathrm{a}$ & 0,373 & 0,281 & 0,374 \\
\hline Firmeza $(\mathrm{N})$ & $8,40 \mathrm{~b}$ & $9,40 \mathrm{a}$ & $<0,001$ & 0,038 & 0,518 \\
\hline Sólidos solúveis ( ${ }^{\circ}$ Brix) & $4,60 \mathrm{~b}$ & $5,20 \mathrm{a}$ & $<0,001$ & 0,044 & 0,251 \\
\hline Acidez titulável $^{3}$ & $0,13 b$ & $0,17 \mathrm{a}$ & $<0,001$ & 0,962 & 0,502 \\
\hline pH da polpa & $6,10 \mathrm{~b}$ & $6,30 \mathrm{a}$ & $<0,001$ & 0,863 & 0,175 \\
\hline Matéria seca (\%) & $18,10 \mathrm{~b}$ & $18,80 \mathrm{a}$ & 0,002 & 0,790 & 0,777 \\
\hline Amido $(\%)^{4}$ & $14,40 \mathrm{~b}$ & $15,70 \mathrm{a}$ & 0,002 & 0,150 & 0,839 \\
\hline Açúcares redutores $(\%)^{4}$ & $0,08 \mathrm{a}$ & $0,08 \mathrm{a}$ & 0,603 & $<0,001$ & 0,573 \\
\hline Teor de proteína $(\%)^{4}$ & $1,90 \mathrm{~b}$ & $2,50 \mathrm{a}$ & $<0,001$ & 0,958 & 0,904 \\
\hline
\end{tabular}

Médias seguidas de letras iguais nas linhas não diferem entre si pelo teste F, 5\% (means followed by the same letter, in the row, do not differ by the $\mathrm{F}$ test, $5 \%$ ); ${ }^{1} \mathrm{PC}=$ Produtividade comercial (marketable yield); ${ }^{2} \mathrm{MMTC}=$ Massa média de tubérculos comercializáveis (average mass of marketable tubers); ${ }^{3}$ Ácido cítrico por $100 \mathrm{~g}$ de matéria fresca (\%) \{citric acid per $100 \mathrm{~g}$ of fresh mass $\left.(\%)\right\} .{ }^{4} \mathrm{Matéria} \mathrm{fresca}(\%)$ $\{$ fresh mass $(\%)\} .{ }^{5} \mathrm{P}$ extraído pelo método da resina (extracted $\mathrm{P}$ by resin method).

plantio maiores que as recomendadas por Miranda Filho (1997).

Não houve diferenças entre as cultivares quanto à massa média de tubérculos comercializáveis nos três experimentos (Tabela 1). Esta variável foi influenciada pelas doses de $\mathrm{P}$ apenas nos solos com baixa e média disponibilidade de P, ou seja, sob elevada disponibilidade de $\mathrm{P}$ o fornecimento desse nutriente via adubação não interferiu no crescimento dos tubérculos. Rosen \& Bierman (2008) verificaram que sob alta disponibilidade de $\mathrm{P}$, além da adubação fosfatada não aumentar o tamanho dos tubérculos, ela diminuiu o número de tubérculos de maior tamanho. No cultivo em solo com baixa disponibilidade de $\mathrm{P}$, a massa média de tubérculos aumentou em $131 \%$ até a dose de $500 \mathrm{~kg} / \mathrm{ha}$ de $\mathrm{P}_{2} \mathrm{O}_{5}$, e mesmo com esse aumento, 


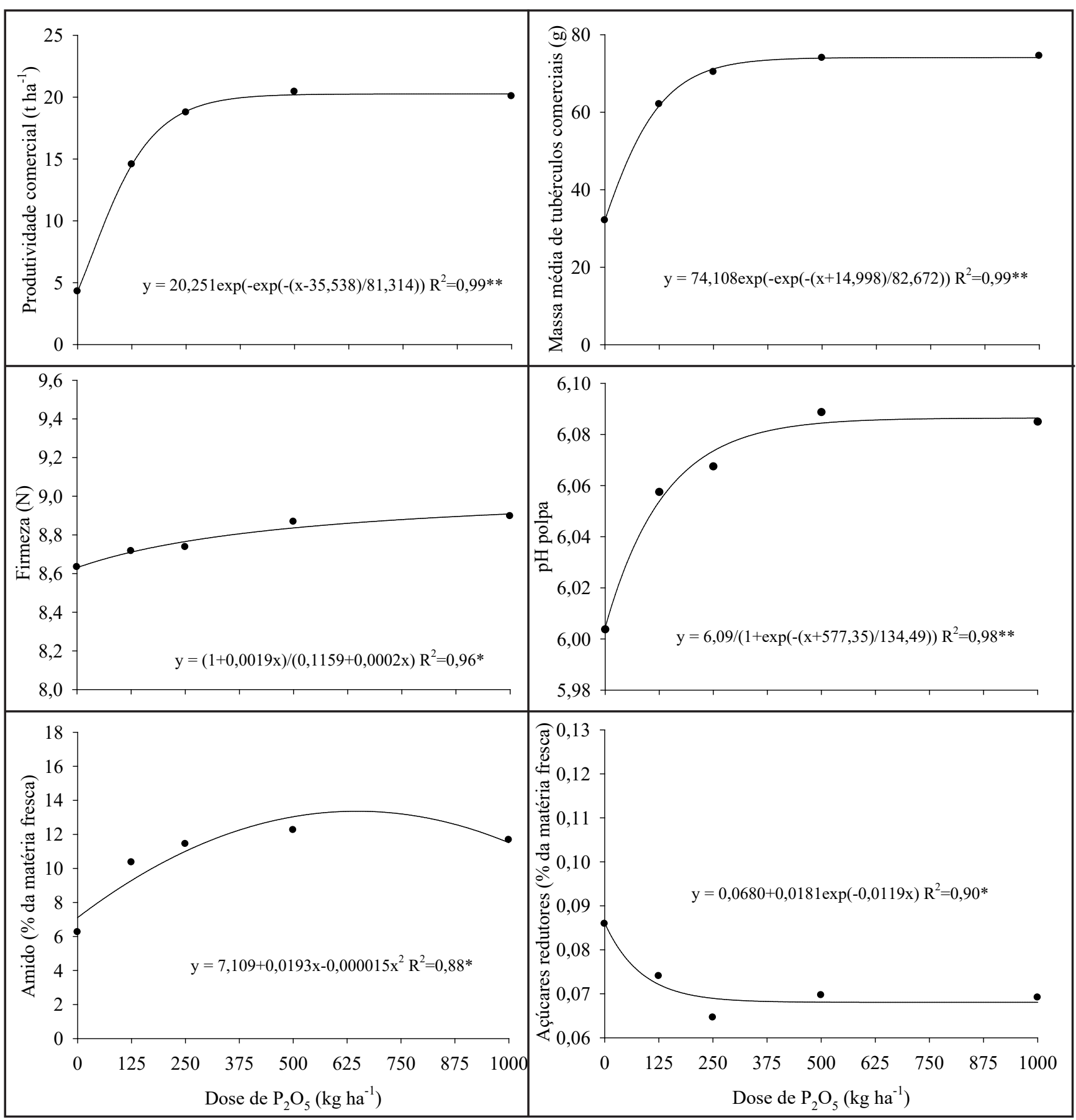

Figura 1. Produtividade e características de qualidade dos tubérculos comercializáveis de cultivares de batata em resposta à adubação fosfatada em solo com baixa disponibilidade de fósforo (yield and quality characteristics of marketable tubers of potato cultivars in response to $\mathrm{P}$ fertilization in soils with low $\mathrm{P}$ availability); $\mathrm{P}_{\text {resina }}=14 \mathrm{mg} / \mathrm{dm}^{3} ; \bullet=$ média das duas cultivares (average of two cultivars); ${ }^{*} \mathrm{p}<0,05$; $* * p<0,01$. Botucatu, UNESP, 2011.

os tubérculos foram menores que no tratamento testemunha do solo com média disponibilidade de $\mathrm{P}$ (Figura $1 \mathrm{~b}$ e $2 b)$. No solo com média disponibilidade de $\mathrm{P}$, os aumentos na massa média de tubérculos foram de apenas $25 \%$ e ocorreram até a dose estimada de 710 $\mathrm{kg} /$ ha de $\mathrm{P}_{2} \mathrm{O}_{5}$ (Figura 2b). Zewide et al. (2012) também verificaram que a adu- bação fosfatada proporcionou aumento na massa média de tubérculos de até $24,5 \%$ em solo de baixa fertilidade, de forma semelhante aos resultados dessa pesquisa. Isso reforça que nos cultivos em solo de baixa disponibilidade de $\mathrm{P}, \mathrm{o}$ fornecimento de P é fundamental para a produção de tubérculos maiores.

Em todos os experimentos, a fir- meza da polpa dos tubérculos sofreu influência dos fatores isolados, com os tubérculos da cultivar Markies sempre apresentando polpa mais firme que os da cultivar Asterix (Tabela 1). Fernandes et al. (2010) e Evangelista et al. (2011), avaliaram possíveis diferenças nas características físico-químicas entre tubérculos de cultivares de batata e 


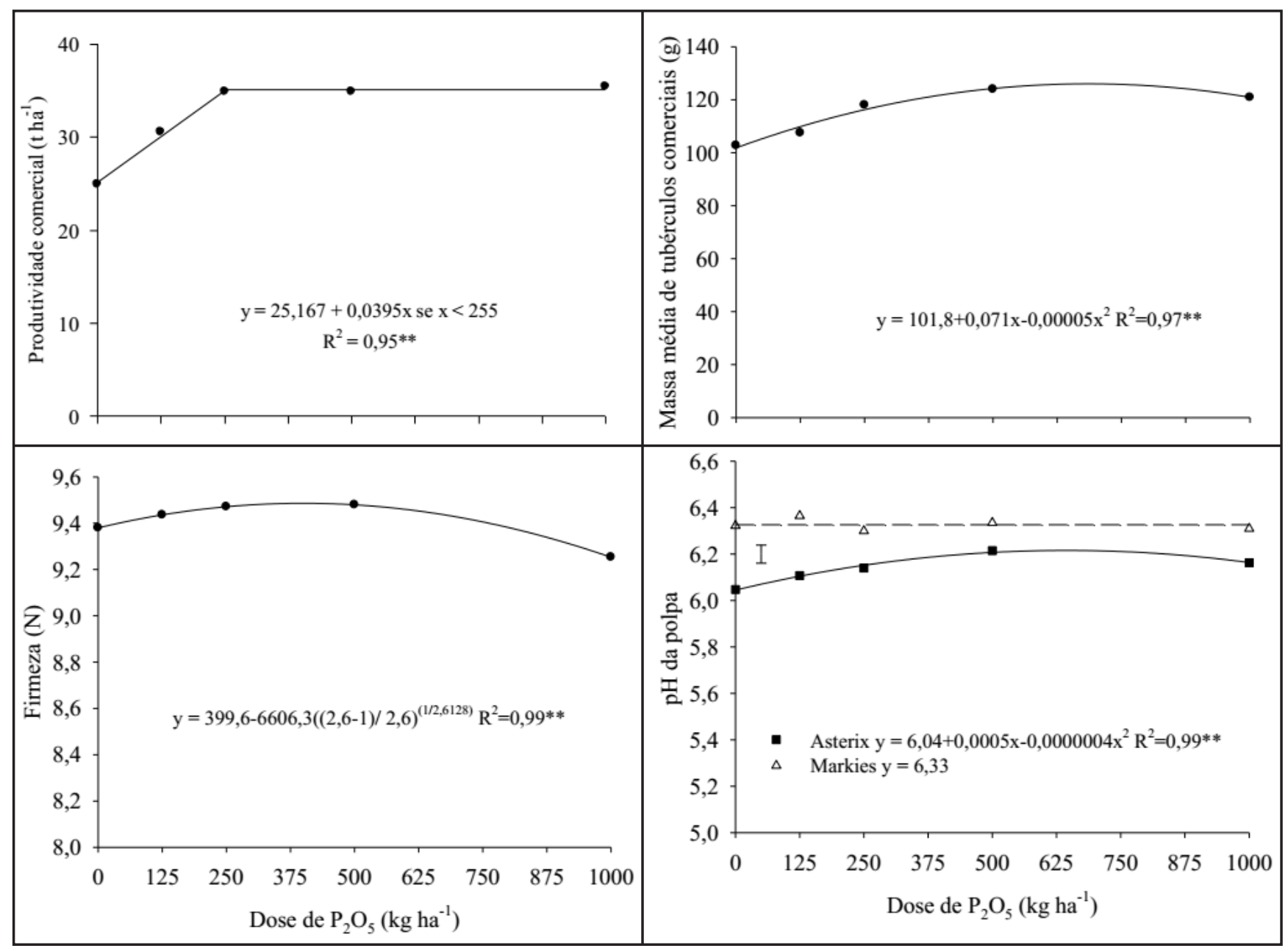

Figura 2. Produtividade e características de qualidade dos tubérculos comercializáveis de cultivares de batata em resposta a adubação fosfatada em solo com média disponibilidade de $\mathrm{P}$ (yield and quality characteristics of tubers of potato cultivars in response to $\mathrm{P}$ fertilization in soils with medium $\mathrm{P}$ availability); $\mathrm{P}_{\text {resina }}=36 \mathrm{mg} / \mathrm{dm}^{3} ; \boldsymbol{\bullet}=$ média das duas cultivares (average of two cultivars); $\mathbf{\square}=$ Asterix; $\triangle=$ Markies. ${ }^{*} \mathrm{p}<0,05 ;{ }^{*} \mathrm{p}<0,01$. Barras verticais indicam o valor de DMS pelo teste de $\mathrm{t}$ a $5 \%$ de probabilidade \{vertical bars represent the Least Significant Difference (LSD) at 5\% probability . Botucatu, UNESP, 2011.

não observaram diferenças entre essas duas cultivares em relação aos valores de firmeza da polpa dos tubérculos, possivelmente por causa das variações no sistema de condução da cultura. No solo com baixo teor de P disponível a adubação fosfatada aumentou a firmeza da polpa dos tubérculos em 3,5\% até a maior dose de P estudada, possivelmente devido aos aumentos expressivos nos teores de amido dos tubérculos (Figura 1c e 1e). Nos cultivos em solos de média e alta disponibilidade de $\mathrm{P}$ os aumentos na firmeza da polpa dos tubérculos foram de $1,2 \%$ e $6,9 \%$, e ocorreram até as doses estimadas de 375 e $625 \mathrm{~kg} / \mathrm{ha}$ de $\mathrm{P}_{2} \mathrm{O}_{5}$, respectivamente (Figuras $2 \mathrm{c}$ e 3b). Isso indica que mesmo em condição de maior disponibilidade de P no solo a adubação fosfatada aumenta a firmeza da polpa dos tubérculos.

Os sólidos solúveis dos tubérculos foram influenciados pelo fator cultivar nas condições de baixa e média disponibilidade de $\mathrm{P}$ e pelos fatores isolados na área com alto teor de $\mathrm{P}$ disponível (Tabela 1). Em todas as áreas os maiores valores de sólidos solúveis foram observados nos tubérculos da cultivar Markies (Tabela 1), o que demonstra que os tubérculos dessa cultivar possuem maior proporção de açúcares, tendo em vista que os sólidos solúveis são constituídos principalmente por açúcares (sacarose) (Fernandes et al., 2010). Fernandes et al. (2010) e Evangelista et al. (2011) também observaram maiores valores de sólidos solúveis nos tubérculos da cultivar Markies em comparação com a Asterix. Apenas na condição de alta disponibilidade de $\mathrm{P}$ a adubação fosfatada promoveu pequenos incrementos nos valores de sólidos solúveis até a dose de $500 \mathrm{~kg} /$ ha de $\mathrm{P}_{2} \mathrm{O}_{5}$, ou seja, nesta condição a adubação fosfatada aumenta a proporção de açúcares presentes nos tubérculos (Tabela 1 e Figura 3c).

A acidez titulável foi influenciada apenas pelo fator cultivar (Tabela 1), em todos os experimentos. Independentemente da disponibilidade de P no solo e da dose de P aplicada no sulco de plantio, a cultivar Markies apresentou tubérculos com acidez titulável cerca de $19 \%$ a $24 \%$ maior que os da cultivar Asterix. Isso demonstra que a polpa dos tubérculos da cultivar Markies possui maior quantidade de ácidos orgânicos dissolvidos nos vacúolos das células na forma livre ou combinada com sais de 


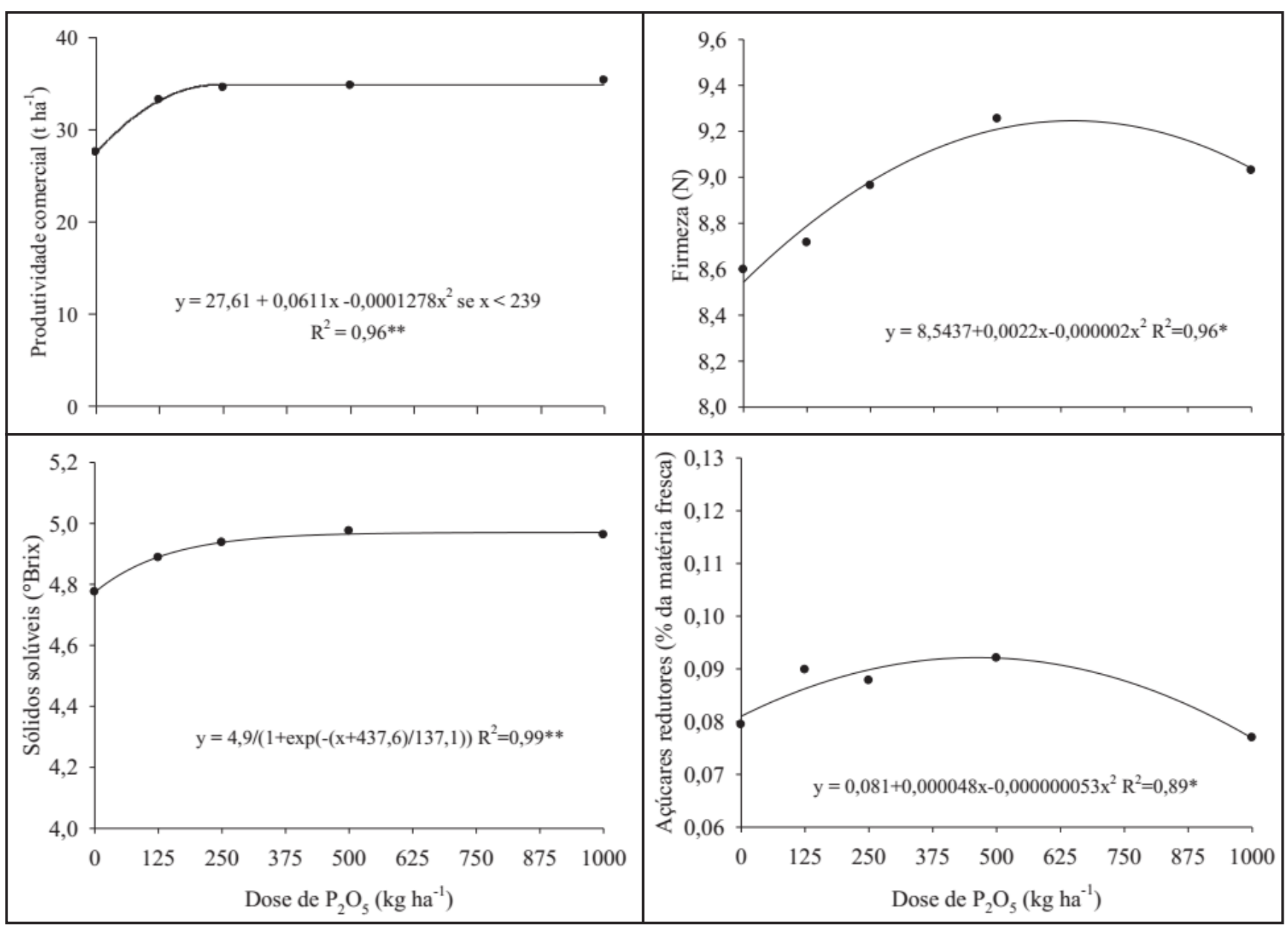

Figura 3. Produtividade e características de qualidade dos tubérculos comercializáveis de cultivares de batata em resposta à adubação fosfatada em solo com alta disponibilidade de fósforo (yield and quality characteristics of marketable tubers of potato cultivars in response to $\mathrm{P}$ fertilization in soils with high $\mathrm{P}$ availability); $\mathrm{P}_{\text {resina }}=70 \mathrm{mg} / \mathrm{dm}^{3} ; \bullet=$ média das duas cultivares (average of two cultivars). ${ }^{*} \mathrm{p}<0,05$; $* * p<0,01$. Botucatu, UNESP, 2011.

ésteres (Nassur, 2009), os quais podem resultar num melhor aroma característico dos tubérculos após o preparo, já que alguns componentes desses ácidos são voláteis (Gouveia et al., 2014).

Nos solos com baixo e alto teores de P disponível, a cultivar Markies apresentou valores de $\mathrm{pH}$ da polpa superiores aos da Asterix (Tabela 1). Fernandes et al. (2010) e Evangelista et al. (2011) também constataram que a cultivar Markies apresentava tubérculos com maior $\mathrm{pH}$ da polpa. No solo com baixa disponibilidade de $\mathrm{P}$, a adubação fosfatada aumentou os valores de $\mathrm{pH}$ da polpa até a dose de $500 \mathrm{~kg} / \mathrm{ha}$ de $\mathrm{P}_{2} \mathrm{O}_{5}$ (Figura 1d). No solo com médio teor de $P$ disponível a adubação não interferiu no $\mathrm{pH}$ da polpa dos tubérculos da cultivar Markies, que nas menores doses de $\mathrm{P}$ apresentou valores de $\mathrm{pH}$ de polpa superiores aos da Asterix (Figura 2d).
No entanto, como a adubação fosfatada aumentou o $\mathrm{pH}$ da polpa dos tubérculos da cultivar Asterix até a dose de 625 $\mathrm{kg} /$ ha de $\mathrm{P}_{2} \mathrm{O}_{5}$, nas maiores doses de $\mathrm{P}$ o $\mathrm{pH}$ da polpa de ambas as cultivares foi similar. Esses resultados indicam que, dependendo da disponibilidade de $\mathrm{P}$ no solo e da cultivar, a adubação fosfatada pode melhorar a qualidade pós-colheita dos tubérculos, pois ela aumenta os valores de $\mathrm{pH}$ da polpa dos tubérculos, o que é importante para a conservação da qualidade, pois as enzimas que degradam o amido apresentam maior atividade em valores de $\mathrm{pH}$ mais baixos (Feltran et al., 2004; Evangelista et al., 2011).

No solo com baixa disponibilidade de P não houve influência dos fatores estudados sobre o percentual de MS dos tubérculos (Tabela 1). Nos solos com maiores teores de P disponível, apenas o fator cultivar afetou a MS de tubérculos, o que indica que independente da disponibilidade de $\mathrm{P}$ no solo, a adubação fosfatada não interferiu na percentagem de MS dos tubérculos. Nos solos com média e alta disponibilidade de $\mathrm{P}$, a cultivar Markies apresentou tubérculos com percentuais de MS superiores aos da Asterix em aproximadamente 3,8\%, fato que não foi observado por Fernandes et al. (2010) e Evangelista et al. (2011). Soratto et al. (2015) observaram que maior disponibilidade de $\mathrm{P}$ no solo aumentou a alocação de MS para os tubérculos da cultivar de Asterix, mas não da Markies. Destaca-se que apesar da adubação fosfatada não ter interferido na percentagem de MS, por ter aumentado a produtividade de tubérculos comercializáveis, levaria à maior produtividade de material processado por área (quantidade de MS de tubérculos). 
Tabela 2. Doses de máxima eficiência agronômica (DMEA) e doses de máxima eficiência econômica (DMEE) da adubação fosfatada em solos com baixa, média e alta disponibilidade de $\mathrm{P}$ \{maximum agronomic efficiency rates (DMEA) and maximum economic efficiency rates (DMEE) of P fertilization in soils with low, medium, and high $\mathrm{P}$ availability $\}$. Botucatu, UNESP, 2011.

\begin{tabular}{|c|c|c|}
\hline \multirow{2}{*}{ Disponibilidade de P no solo ${ }^{1}$} & DMEA & DMEE \\
\hline & \multicolumn{2}{|c|}{$\left(\mathrm{kg} / \mathrm{ha}\right.$ de $\left.\mathrm{P}_{2} \mathrm{O}_{5}\right)$} \\
\hline Baixa $\left(14 \mathrm{mg} / \mathrm{dm}^{3}\right)$ & 500 & 358 \\
\hline Média $(36$ mg/dm³ $)$ & 255 & 255 \\
\hline Alta $\left(70 \mathrm{mg} / \mathrm{dm}^{3}\right)$ & 239 & 220 \\
\hline
\end{tabular}

${ }^{1} \mathrm{P}$ extraído pelo método da resina (P extracted by resin method).

O teor de amido foi influenciado pelas doses de $\mathrm{P}$, no solo com baixo teor de P disponível, e apenas pelas cultivares nos solos com maior disponibilidade de $\mathrm{P}$ (Tabela 1). Isso demonstra que, em solos com maior fertilidade em $\mathrm{P}$, este nutriente que estava disponível no solo foi suficiente para promover o crescimento e acúmulo de amido nos tubérculos. No solo com baixa disponibilidade de $\mathrm{P}$, a adubação fosfatada aumentou o teor de amido dos tubérculos até a dose estimada de 643 $\mathrm{kg} / \mathrm{ha}$ de $\mathrm{P}_{2} \mathrm{O}_{5}$ (Figura 1e), o que indica que, sob baixa disponibilidade de $\mathrm{P}$ no solo, o fornecimento desse nutriente é fundamental para promover a síntese e o acúmulo de amido nos tubérculos e o desenvolvimento adequado deste órgão (Houghland, 1960). Sob médio teor de P disponível no solo, os tubérculos da cultivar Asterix apresentaram teores de amido maiores que os da cultivar Markies, mas na condição de alta disponibilidade de P ocorreu o inverso (Tabela 1). No entanto, outros autores obtiveram teores similares de amido nos tubérculos dessas duas cultivares (Fernandes et al., 2010; Evangelista et al., 2011).

O teor de açúcares redutores dos tubérculos foi influenciado apenas pela cultivar, na condição de média disponibilidade de P no solo, e pelas doses de $\mathrm{P}$ nos solos com baixo e alto teores de P disponível (Tabela 1). No solo com médio teor de $\mathrm{P}$ disponível, a cultivar Markies apresentou teores de açúcares redutores nos tubérculos $18,2 \%$ maiores que a Asterix. No entanto, em outras pesquisas foi observada a presença de teores similares de açúcares redutores nos tubérculos dessas cultivares (Fernandes et al., 2010), ou até teores mais elevados nos tubérculos da cultivar
Asterix (Evangelista et al., 2011), o que indica que os teores de açúcares redutores dos tubérculos podem variar dependendo da época de plantio, do ponto de colheita e das cultivares utilizadas (Robles, 2003).

No solo com baixo teor de P disponível a adubação fosfatada diminuiu os teores de açúcares redutores até a dose de $250 \mathrm{~kg} /$ ha de $\mathrm{P}_{2} \mathrm{O}_{5}$ (Figura 1f), o que é uma característica importante para a indústria de processamento (Pereira et al., 2007; Quadros et al., 2010). Essa redução nos teores de açúcares redutores ocorreu, possivelmente, porque com a adubação fosfatada as plantas de batata aumentaram a conversão dos açúcares redutores (glicose e frutose) dos tubérculos em amido, como se verifica pelos aumentos expressivos nos teores de amido dos tubérculos, em resposta à adubação (Figuras 1e e 1f). No cultivo em solo com alta disponibilidade de $\mathrm{P}$, a adubação fosfatada não aumentou os teores de amido dos tubérculos (Tabela 1) e a aplicação de $P$ aumentou os teores de açúcares redutores dos tubérculos até a dose estimada de $453 \mathrm{~kg} / \mathrm{ha}$ de $\mathrm{P}_{2} \mathrm{O}_{5}$ (Figura 3d), o que indica que sob elevada disponibilidade de $\mathrm{P}$ a aplicação de doses inferiores a esta não aumenta a taxa de conversão de açúcares em amido. Esse aumento nos teores de açúcares redutores com a adubação fosfatada em condição de alta disponibilidade de $\mathrm{P}$ no solo não é interessante para o processamento industrial, porque altos teores de açúcares redutores causam escurecimento indesejável da batata durante a fritura, reduzindo sua aceitação comercial (Fernandes et al., 2010; Quadros et al., 2010). No entanto, mesmo com a adubação aumentando os teores de açúcares redutores nos tubér- culos, estes ficaram abaixo de $0,12 \%$ da massa fresca, o que indica que estavam adequados para serem processados na forma de palitos (Stark et al., 2003; Pereira et al., 2007), que é a principal forma de processamento dos tubérculos dessas cultivares.

O teor de proteína dos tubérculos foi influenciado apenas pelo fator cultivar em todas as condições de disponibilidade de $\mathrm{P}$ no solo, sendo que os tubérculos da cultivar Markies sempre apresentaram teores mais elevados (Tabela 1). Especialmente quando a batata é consumida na forma de massa e saladas, um maior teor de proteína nos tubérculos é interessante, pois, embora apresentem teores de proteína não muito elevados (Lachman et al., 2005), os tubérculos possuem proteína de alto valor nutritivo, podendo ser considerados como importante fonte de proteína (Pereira et al., 2005). Por outro lado, os teores mais elevados de proteína nos tubérculos da cultivar Markies podem não ser interessantes para a indústria de batata palito, porque durante o processo de fritura os açúcares redutores e os aminoácidos, peptídeos ou proteínas presentes nos tubérculos, podem reagir e causar o escurecimento não enzimático (reação de Maillard) e desenvolver coloração escura no produto final (Low et al., 1989).

Diante dos resultados obtidos concluiu-se que, independentemente da disponibilidade de P no solo e da adubação fosfatada, a cultivar Markies foi menos produtiva que a Asterix, porém com tubérculos de qualidade superior quanto as características firmeza, sólidos solúveis, acidez titulável, $\mathrm{pH}$ da polpa e teor de proteína. Em solo com baixa, média e alta disponibilidade de $\mathrm{P}$, as produtividades de tubérculos comercializáveis, de ambas as cultivares, foram incrementadas em $376 \%, 41 \%$ e $26 \%$, respectivamente, até as DMEA de 500, 255 e $239 \mathrm{~kg} / \mathrm{ha}$ de $\mathrm{P}_{2} \mathrm{O}_{5}$. As DMEE nos solos com baixa, média e alta disponibilidade de $\mathrm{P}$ foram de 358,255 e 220 $\mathrm{kg} / \mathrm{ha}$ de $\mathrm{P}_{2} \mathrm{O}_{5}$, respectivamente. Sob baixa disponibilidade de $\mathrm{P}$, a adubação fosfatada melhorou a qualidade dos tubérculos, aumentando a massa média, a firmeza, o pH da polpa e o teor de amido, e diminuindo o teor de açúcares 
redutores. Nos solos com maiores teores de $\mathrm{P}$ disponível, além de ter exercido menor influência sobre a produtividade e qualidade dos tubérculos, a adubação fosfatada aumentou os teores de açúcares redutores dos tubérculos até a dose de $453 \mathrm{~kg} /$ ha de $\mathrm{P}_{2} \mathrm{O}_{5}$, o que não é interessante para o processamento industrial da batata.

\section{AGRADECIMENTOS}

À Fundação de Amparo a Pesquisa do Estado de São Paulo (FAPESP) pela concessão de bolsa ao primeiro autor (Proc. 2010/04987-6); ao Conselho Nacional de Desenvolvimento Científico $(\mathrm{CNPq})$ pelo suporte à pesquisa $\mathrm{e}$ concessão de bolsa de Produtividade em Pesquisa ao segundo autor e ao Grupo Ioshida por ceder as áreas para condução dos experimentos. À Associação Brasileira da Batata (ABBA) pela doação de tubérculos-semente. À Dra. Maria Márcia P. Sartori pelo auxílio no ajuste das equações.

\section{REFERÊNCIAS}

ABBA - ASSOCIAÇÃO BRASILEIRA DA BATATA. 2010. Variedades. Batata Show 10: $1-4$.

BÉLANGER, G; WALSH, JR; RICHARDS, JE; MILBURN, PH; ZIADI, N. 2000. Comparison of three statistical models describing potato yield response to nitrogen fertilizer. Agronomy Journal 92: 902-908.

CEPEA/ESALQ/USP - Centro de Estudos Avançados em Economia Aplicada. 2012, janeiro/fevereiro. Batata. Disponível em: http://www.cepea.esalq.usp.br/hfbrasil/ edicoes/109/full.pdf.

EVANGELISTA, RM; NARDIN, I; FERNANDES, AM; SORATTO, RP. 2011. Qualidade nutricional e esverdeamento pós-colheita de tubérculos de cultivares de batata. Pesquisa Agropecuária Brasileira 46: 953-960.

FELTRAN, JC; LEMOS, LB; VIEITES, RL. 2004. Technological quality and utilization of potato tubers. Scientia Agrícola 61: 598-603.

FERNANDES, AM; SORATTO, RP. 2012. Nutrição mineral, calagem e adubação da batateira. Botucatu/Itapetininga: FEPAF/ ABBA. 121p.

FERNANDES, AM; SORATTO, RP; EVANGELISTA, RM; NARDIN, I. 2010. Qualidade físico-química e de fritura de tubérculos de cultivares de batata na safra de inverno. Horticultura Brasileira 28: 299-304.

FERNANDES, AM; SORATTO, RP;
EVANGELISTA, RM; SILVA, BL; SOUZASCHLICK, GD. 2011b. Produtividade e esverdeamento pós-colheita de tubérculos de cultivares de batata produzidos na safra de inverno. Revista Ciência Agronômica 42: 502-508.

FERNANDES, AM; SORATTO, RP; SILVA, BL. 2011a. Extração e exportação de nutrientes em cultivares de batata: I - Macronutrientes. Revista Brasileira de Ciência do Solo 35: 2039-2056.

FONTES, PCR; ROCHA, FAT; MARTINEZ, HEP. 1997. Produção de máxima eficiência econômica da batata em função da adubação fosfatada. Horticultura Brasileira 15: 104107.

FREEMAN, KL; FRANZ, PR; JONG, RW. 1998. Effect of phosphorus on the yield, quality and petiolar phosphorus concentrations of potatoes (cv. Russet Burbank and Kennebec) grown in the krasnozem and duplex soils of Victoria. Australian Journal of Experimental Agriculture 38: 83-93.

GOUVEIA, MAS; CORREIA, CV; TAVARES, AE; EVANGELISTA, RM; CARDOSO, AII. 2014. Qualidade de raízes de batatadoce em função da adubação nitrogenada e conservação. Revista Raízes e Amidos Tropicais 10: 57-64.

HOCHMUTH, G; WEINGARTNER, P; HUTCHINSON, C; TILTON, A; JESSEMAN, D. 2002. Potato yield and tuber quality did not respond to phosphorus fertilization of soil testing high in phosphorus content. HorTechnology 12: 420-422.

HORWITZ, W; LATIMER JUNIOR, GW. 2005. Official methods of analysis of the Association of Analytical Chemists International. 18 ed. Gaythersburg: AOAC International. $1141 \mathrm{p}$.

HOUGHLAND, GVC. 1960. The influence of phosphorus on the growth and physiology of the potato plant. American Potato Journal 37: 127-138.

KLEIN, LB; CHANDRA, S; MONDY, NI. 1980. The effect of phosphorus fertilization on the chemical quality of Katahdin potatoes. American Potato Journal 57: 259-266.

LACHMAN, J; HAMOUZ, K; DVORÁK, P; ORSÁK, M. 2005. The effect of selected factors on the content of protein and nitrates in potato tubers. Plant, Soil and Environment 51: 431-438.

LOW, N; JIANG, Z; OORAIKUL, B; DOKHANI, S; PALCIC, MM. 1989. Redution of glucose content in potatoes with glucose oxidase. Journal of Food Science 54: 118-121.

MIRANDA FILHO, HS. 1997. Batata. In: RAIJ, B; CANTARELla, H; QUAGgIO, JA; FURLANI, AMC (eds). Recomendações de adubação e calagem para o Estado de São Paulo. Campinas: Instituto Agronômico, p. 225. (Boletim Técnico, 100).

MÜLLER, DR; BISOGNIN, DA; ANDRIOLO, JL; MORIN JUNIOR, GR; GNOCATO, FS. 2009. Expressão dos caracteres e seleção de clones de batata nas condições de cultivo de primavera e outono. Ciência Rural 39: 1327-1334.

NASSUR, RCMR. 2009. Qualidade pós colheita de tomate italiano produzido em sistema orgânico. Lavras: UFLA. 127p. (Dissertação mestrado).

NAVA, G; DECHEN, AR; IUCHI, VL. 2007. Produção de tubérculos de batata-semente em função das adubações nitrogenada, fosfatada e potássica. Horticultura Brasileira 25: 365-370.

NELSON, NA. 1944. A photometric adaptation of Somogy method for determination of glucose. Journal of Biological Chemistry 153: 375-390.

NOVAIS, RF; SMYTH, TJ. 1999. Fósforo em solo e planta em condições tropicais. Viçosa: UFV, 399p.

PEREIRA, AS; FRITSCHE NETO, R; SILVA, RS; BENDER, CI; SCHÜNEMANN, AP; FERRI, NM; VENDRUSCOLO, JL. 2007. Genótipos de batata com baixo teor de açúcares redutores. Horticultura Brasileira 25: 220-223.

PEREIRA, EMS; LUZ, JMQ; MOURA, CC. 2005. A batata e seus beneficios nutricionais. Uberlândia: EDUFU, 60p.

QUADROS, DA; JUNG, MC; FERREIRA, SMR; FREITAS, RJS. 2009. Composição química de tubérculos de batata para processamento, cultivados sob diferentes doses e fontes de potássio. Ciência e Tecnologia de Alimentos 29: 316-323

QUADROS, DA; JUNG, MC; FERREIRA, SMR; FREITAS, RJS. 2010. Qualidade de batata para fritura, em função dos níveis de açúcares redutores e não-redutores, durante o armazenamento à temperatura ambiente. Acta Scientiarum Technology 32: 439-443.

QUEIROZ, LRM; KAWAKAMI, J; MULLER, MML; OLIARI, ICR; UMBURANAS, RC; ESCHEMBACK, V. 2013. Adubação NPK e tamanho da batata-semente no crescimento, produtividade e rentabilidade de plantas de batata. Horticultura Brasileira 31: 119-127.

RAIJ, B; ANDRADE, JC; CANTARELLA, H; QUAGGIO, JA. 2001. Análise química para avaliação da fertilidade de solos tropicais. Campinas: Instituto Agronômico, 284p.

RAIJ, B; CANTARELLA, H; QUAGGIO, JA; FURLANI, AMC (eds). 1997. Recomendações de adubação e calagem para o Estado de São Paulo. Campinas: Instituto Agronômico, 285p. (Boletim Técnico, 100).

RAMOS, RM; SILVA, AR; DUMBRA, JGR. 2013. O aquecido mercado dos vegetais congelados: Brasil tem grande potencial para expandir a indústria nacional. Hortifruti Brasil 11: 8-21.

ROBLES, WGR. 2003. Dióxido de carbono via fertirrigação em batateira (Solanum tuberosum L.) sob condições de campo. Piracicaba: USP/ ESALQ. 160p. (Tese doutorado).

ROSEN, CJ; BIERMAN, PM. 2008. Potato yield and tuber set as affected by phosphorus fertilization. American Journal of Potato Research 85: 110-120.

ROSEN, CJ; KELLING, KA; STARK, JC; PORTER, GA. 2014 Optimizing phosphorus fertilizer management in potato production. American Journal of Potato Research 91: 145-160.

SANYAL, SK; DATTA, SK. 1991. Chemistry of phosphorus transformations in soil. Advances in Soil Science 16: 1-120.

Hortic. bras., v. 34, n. 3, jul. - set. 2016 
SORATTO, RP; FERNANDES, AM; SOUZASCHLICK, GD. 2011. Extração e exportação de nutrientes em cultivares de batata: II Micronutrientes. Revista Brasileira de Ciência do Solo 35: 2057-2071.

SORATTO, RP; PILON, C; FERNANDES, AM; MORENO, LA. 2015. Phosphorus uptake, use efficiency, and response of potato cultivars to phosphorus levels. Potato Research 58:
121-134.

STARK, JC; OLSEN, N; KLEINKOPF, GE; LOVE, SL. 2003. Tuber quality. In: STARK, JC; LOVE, SL (eds). Potato production systems. Aberdeen: University of Idaho. p. 329-343.

ZENEBOM, O; PASCUET, NS. 2005. Ministério da Saúde. Agência Nacional de Vigilância Sanitária. Métodos físico-químicos para análise de alimentos. 4. ed. Brasília: Ministério da Saúde, $1018 \mathrm{p}$

ZEWIDE, I; MOHAMMED, A; TULU, S. 2012. Effect of different rates of nitrogen and phosphorus on yield and yield components of potato (Solanum tuberosum L.) at Masha District, Southwestern Ethiopia. International Journal of Soil Science 7: 146-1156. 